Research Article

\title{
Effect of Alloying Composition on Microstructure and Mechanical Properties of Ultranarrow Gap Welded Joints of U71Mn Rail Steel
}

\author{
Lian Gong $\mathbb{D}$, Hui Liu, Cheng Lv, and Lijun Zhao \\ School of Intelligent Manufacturing Engineering, Chongqing University of Arts and Science, Chongqing 402160, China \\ Correspondence should be addressed to Lian Gong; gl2017@cqwu.edu.cn
}

Received 6 August 2021; Revised 13 November 2021; Accepted 18 November 2021; Published 10 December 2021

Academic Editor: Antonio Riveiro

Copyright ( 92021 Lian Gong et al. This is an open access article distributed under the Creative Commons Attribution License, which permits unrestricted use, distribution, and reproduction in any medium, provided the original work is properly cited.

\begin{abstract}
A new welding method, ultranarrow gap welding with constrained arc by flux band, is proposed to compensate for the low quality of rail thermite welded joints. This article presents the results of research on the microstructure and mechanical properties of ultranarrow gap welded joints of U71Mn rail steel made using three types of alloying composition content flux bands. Results indicated that the base metal metallographic microstructure consisted mainly of pearlitic, the HAZ was mainly composed of fine pearlite, and the microstructure of the welded bead was composed of acicular ferrite, while the weld grain size decreased as the alloy composition increased. The average hardness noticeably changed in weld metal as the alloy composition increased, and when the alloy composition reached $19 \%$, the hardness was equivalent to the base material. The average hardness value of the HAZ (35.8 HRC) was higher than that of the base metal $(24.8 \mathrm{HRC})$. The tensile strength increased, and the percentage elongation after fracture decreased with increasing alloying composition from $9 \%$ to $19 \%$. The impact absorbing energies were decreased as the alloying composition increased. Consequently, all the mechanical properties of rail ultranarrow gap welding were higher than those of the standard requirements of the rail flash welding. And the optimal alloying composition of flux band was $19 \%$.
\end{abstract}

\section{Introduction}

Nowadays, there are mainly two types of welding processes applied in continuous welded rails: electric flash-butt welding and thermite welding $[1,2]$. Flash-butt welding is recognized as the most reliable [3] and the most stable welding method [4] for welding rails; however, this method cannot be applied to rail locking welding [5] because it requires a breaking force at the end, so it can only be used in workshops [6]. Rail in situ welding of the field had to use the aluminothermic technique, but thermite welding is a casting method [7]. Due to overheating of the weld metal and surrounding zone, the joint has many initial defects, including the lack of fusion, shrinkage cavities, cold-lap, center-line defects clusters, microporosities, and entrapped slag [8-10]. Fracture and fatigue damage in thermite welded rail joints is a frequent source of service failures in railway infrastructure [11], which has a major impact on rail service reliability and safety [12]. Thus, it can be seen that the rail in situ welding is the weakest link in the overall welding quality of the seamless line. It is of great significance to develop an efficient and stable welding technology to change the single and poor quality of in situ welding of rail in China.

In this paper, ultranarrow gap welding with a constrained arc by flux band is applied to rail in situ welding [13]. In this method, an I-shaped groove with a gap width of $4 \mathrm{~mm}$ is adopted to conduct multilayer single-channel ultranarrow gap welding by using a flux band to constrain the melting electrode arc. The energy of single-layer welded wire is only $0.5 \mathrm{~kJ} / \mathrm{mm}$ [14], which can reduce grain size in welding, decrease the welding heat-affected zone (the width of HAZ is only about $2 \mathrm{~mm}$ ), and eliminate intenerating and strength loss problems of the heat-affected zone for high-strength steel welding [15]. At the same time, the narrow groove width and less welding wire filling can greatly reduce the pure welding time. It just needs to take about 10 minutes to complete the whole pair of rails welding [16]. Therefore, it is of great significance to apply ultranarrow gap welding with a flux band constrained arc to the rail in situ welding.

A series of problems have been solved in the preliminary study. The formation mechanism of cold 
cracks in the heat-affected zone was because the rail belongs to high carbon steel, with its carbon equivalent $\mathrm{CE}=1.02 \%>0.6 \%$, which had a large tendency of hardening and high sensitivity to cold cracks [17]. When the preheating temperature was finally determined to be $300^{\circ} \mathrm{C}$, the cold cracks could be avoided [18]. The formation mechanism of a hot crack in weld metal was because of the high content of S and P in U71Mn, eutectic liquid film with a low melting point was formed, which made it easy to form crystal cracks under the action of tensile stress during solidification and contraction of welding seams [19], and hot crack could be avoided by using a specification that can form a large forming coefficient during welding [20]. Wang et al. [21] studied the arc behavior before and after sticking the flux bands to the ultranarrow gap groove, pointing out that the flux bands are beneficial to the increase of the effective heating area of the arc. Fu et al. [22] systematically studied the relationship between the angular deformation and the thickness of the welding layer during ultranarrow gap welding of rail, pointing out that the angular distortion reached a maximum when the thickness of the welding layer was in the range of $13 \sim 18 \mathrm{~mm}$, and there was no more obvious distortion when it was above $100 \mathrm{~mm}$. An exploratory ultranarrow gap welding test for U71 Mn rail was conducted, and it was found that the hardness of the weld zone decreased sharply when preheating at $400^{\circ} \mathrm{C}$ [23].

Therefore, we have obtained a set of optimal welding processes according to the previous research results, but the microstructure and mechanical properties of the joint have not been studied. So in this paper, we intend to change the alloying composition content of flux bands to study the effect of this change on the microstructure and mechanical properties of ultranarrow gap welded joints of U71Mn rail steel. Consequently, we obtain the best flux band composition.

\section{Materials and Methods}

2.1. Materials. The welding operation was done in situ between two lengths of new rails, each approximately $1 \mathrm{~m}$ long. The rails (type U71Mn) were $176 \mathrm{~mm}$ in height (Figure 1), and the materials that were used for welding were pearlitic rail steel. H08Mn2Si welding wire of $1.6 \mathrm{~mm}$ in diameter was used for depositing the weld beads. The chemical composition of base metal and weld metal is shown in Table 1 . The welding method was ultranarrow gap welding with a constrained arc by flux band. The pearlitic steel had a high carbon content, and the filler wire had a very low carbon content. So we added some alloying elements (Mn, Ni, Mo, and $\mathrm{Cr}$ ) into the flux bands. The addition of $\mathrm{Mn}, \mathrm{Ni}, \mathrm{Mo}$, and $\mathrm{Cr}$ was used to increase the hardenability, toughness, and ductility of the weld. In this study, we have chosen three different flux components to put to the test, and the chemical composition of flux bands is shown in Table 2.

2.2. Methods. A schematic diagram of the experimental apparatus is shown in Figure 2(a). Both specimens had an I-shape groove with a gap width of $4.5 \mathrm{~mm}$ and a groove angle of $1.58^{\circ}$, and two crawler-type heaters were used to heat the rail steel to the desired preheat temperature of $573 \mathrm{~K}$ $\left(300^{\circ} \mathrm{C}\right)$ before welding. This preheat temperature was found to be the optimum to prevent the formation of cold cracks and to lower residual stress, then adhering the flux bands with a $0.7 \mathrm{~mm}$ thickness onto the sidewalls of the groove to weld, the main effect of the flux bands was to control the arc, produce $\mathrm{CO}_{2}$ gas, slag to shield the pool, and provide alloying elements for the pool. The flux bands are shown in Figure 2(b). The whole rail joint was then welded using a single-pass multilayer weld until the joint was completely filled. A heat input of $0.5 \mathrm{~kJ} / \mathrm{mm}$ and a wire feed speed of $10 \mathrm{~mm} / \mathrm{s}$ were employed. After finishing three pairs of rai welding, sections of rail approximately $100 \mathrm{~mm}$ long with the weld in the middle were extracted from the welded rails using a rail cutter, and specimens were machined from the welded rail section in the longitudinal direction. The microstructure of the parent steel and its corresponding HAZ and welded material after welding were studied using the JSM-6700F scanning electron microscope (SEM).

Hardness measurements were recorded using a 600D Rockwell hardness tester. The basic mechanical property indices, such as ultimate tensile strength $\mathrm{Rm}$ and percentage elongation after fracture $\delta$ were obtained using CSS-2205 electronic universal testing machines. The Charpy impact energy versus temperature curves were evaluated by Charpy U-Notch impact tests at several temperature points. Six temperature points, i.e., $+20^{\circ} \mathrm{C}, 0^{\circ} \mathrm{C},-20^{\circ} \mathrm{C},-40^{\circ} \mathrm{C},-60^{\circ} \mathrm{C}$, and $-80^{\circ} \mathrm{C}$, were selected for the series of tests. The equipment used was the JBD-300D ultralow temperature impact testing machine.

\section{Test Results and Analysis}

\subsection{Microstructure of U71Mn Rail Base Metal and Weld Joints.} In Figure 3, a macroscopic picture of the longitudinal section of the rail ultranarrow gap weld zone is shown. It could be seen from the figure that the whole rail joint was filled with 50 welding passes, the width of the weld zone was about $6 \mathrm{~mm}$, and the heat-affected zone was only about $2 \mathrm{~mm}$. There were no hot cracks in the weld because the weld forming coefficient of each layer of weld was greater than 1 , and the typical test specimen was taken from the head of the rail to observe the microstructure. The microstructure of the parent rail, HAZ, fusion zone, and weld of the pearlitic rail steels was studied by using a scanning electron microscope. All micrographs were etched with $4 \%$ nital, which was a solution containing 4\% nitric acid and 96\% ethanol, and captured at 1000-3000 times magnification.

Figure 4 shows the macroscopic morphology of the welded joint at the rail head position. Figure $4(\mathrm{a})$ is the parent U71Mn rail steel, which consisted of a fully pearlitic microstructure, a pearlitic microstructure contained parallel plates of alternating ferrite and cementite strips known as lamellae. The cementite was a very hard carbide phase, while the ferrite was a soft ductile phase. The microstructural examination of the HAZ zone is shown in Figures 4-(b)4(d), three regions were identified. Region 1 occurred near the base metal and was called the incomplete recrystallized zone; 


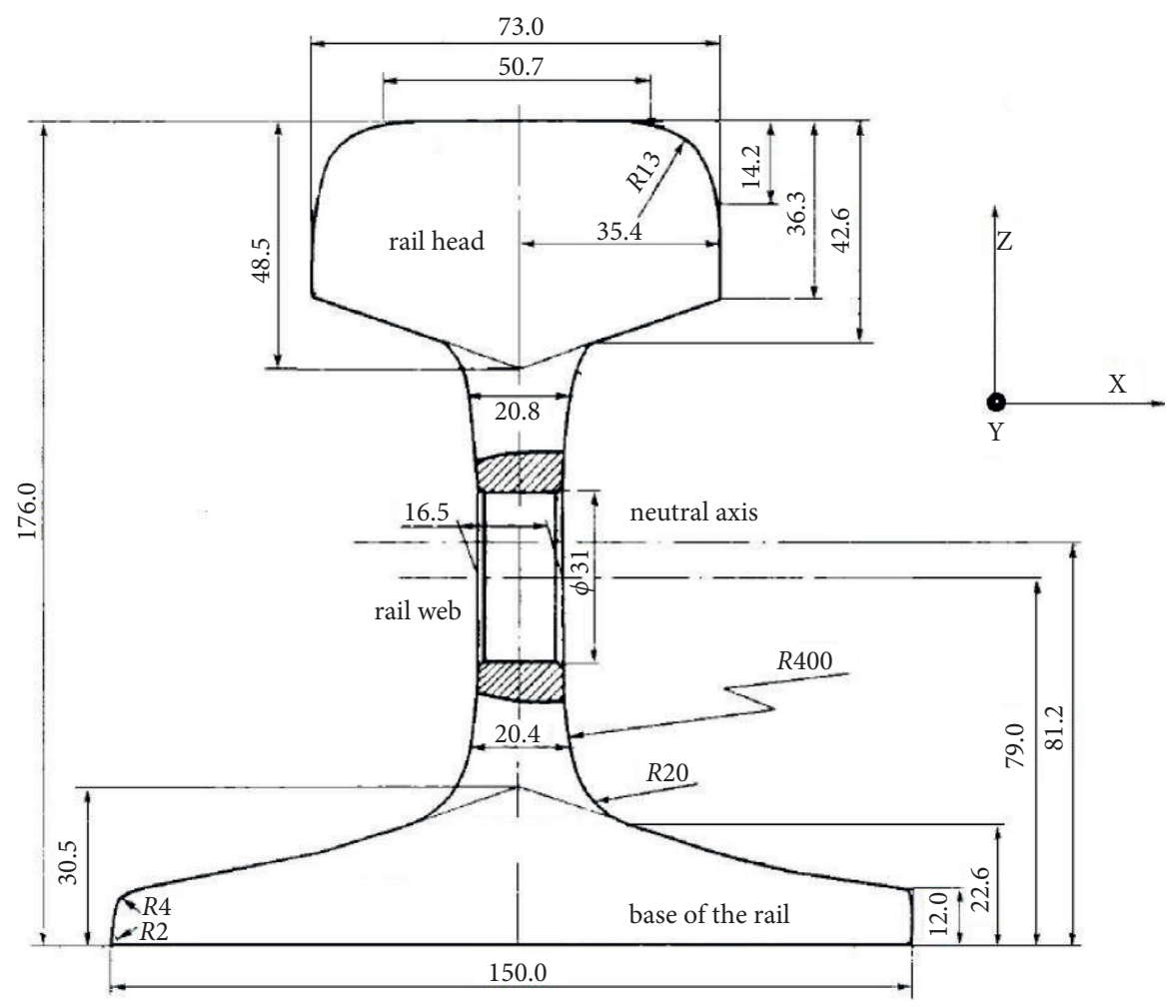

FIGURE 1: U71Mn rail profile (dimensions in $\mathrm{mm}$ ).

TABLe 1: Chemical composition of rail steel and welding wire (wt $\%)$.

\begin{tabular}{lccccccc}
\hline Materials & $\mathrm{C}$ & $\mathrm{Mn}$ & $\mathrm{Si}$ & $\mathrm{S}$ & $\mathrm{P}$ & $\mathrm{Cr}$ & $\mathrm{Ni}$ \\
\hline U71Mn rail steel & 0.72 & 1.21 & 0.22 & 0.006 & 0.018 & - & - \\
H08Mn2Si & 0.11 & 1.9 & 0.8 & 0.03 & 0.03 & 0.2 & 0.2
\end{tabular}

Table 2: Chemical composition of flux band (wt\%).

\begin{tabular}{lcccccccc}
\hline Flux band & $\mathrm{CaCO}_{3}$ & $\mathrm{CaF}_{2}$ & $\mathrm{MnFe}$ & $\mathrm{Cr}$ & $\mathrm{Mo}$ & $\mathrm{Ni}$ & $\mathrm{TiO}_{2}$ & $\mathrm{NaHCO}_{3}$ \\
\hline Formula 1 & 63 & 31 & 0 & 0 & 0 & 0 & 5 & 1 \\
Formula 2 & 55 & 30 & 4 & 3 & 2 & 0 & 5 & 1 \\
Formula 3 & 49 & 26 & 5 & 4 & 2 & 8 & 5 & 1 \\
\hline
\end{tabular}

the microstructure of this area was fine pearlite and is shown in Figure 4(b), and this region's width was $0.5 \mathrm{~mm}$. Region 2 was near the middle of the HAZ zone and was called the recrystallized zone, the width of this region was $0.85 \mathrm{~mm}$, and the microstructure of this region included fine pearlite grains and small amount of ferrite and is shown in Figure 4.(c) Region 3 was near the fusion line called the overheated zone, as shown in Figure 4(d), and it contained mainly fine pearlite with a small amount of grain boundary cementite, the width of this region was $1.05 \mathrm{~mm}$. The welded fusion zone can be seen in Figure 4(e), which showed the HAZ to the left and the weld to the right, consisted of mainly acicular ferrite and pearlite, the width of this region was just $30 \mu \mathrm{m}$.

Figure 5 shows the microstructure of weld metal which was obtained by three various flux composition tests. It could be seen that in the ultranarrow gap welding, each weld bead consisted of two regions "A" and "B," as shown in Figure 5(a). " $A$ " represents the original weld microstructure, and " $\mathrm{B}$ " represents the heat-affected zone microstructure of the weld metal which was mainly caused by the remelting of weld passes. Figure 5(b) shows the microstructure of the weld with no alloying elements in flux bands. The part of " $\mathrm{A}$ " was composed of mainly acicular ferrite and a small amount of pearlite proeutectoid ferrite precipitated along the columnar grains and lath ferrite distributed between the two columnar grains boundary. Polygonal ferrite, acicular ferrite, and pearlite are shown in the part of "B". Figure 5(c) shows the microstructure of a weld with 9\% alloying elements (Mn, Mo, and $\mathrm{Cr}$ ) in flux bands, and Figure 5(d) has $19 \%$ alloying elements (Mn, Mo, Cr, and Ni). It could be seen that the microstructures of " $A$ " area and " $B$ " area of Figures 5(c) and 5(d) are acicular ferrite, and all of the grains are equiaxed.

When compared Figures 5(b)-5(d), it was found that the microstructure of the weld zone was significantly different; the region ' $A$ ' had no dendritic grains after alloying elements were added, and all the regions' grains became fine. This was mainly because the manganese, molybdenum, and chromium added in the flux bands into the weld metal could inhibit the formation of proeutectoid ferrite and promote the formation of acicular ferrite, and the whole alloying elements had the effect of refining grain. By comparing Figures 5(c) and 5(d), it was found that the grain size of acicular ferrite grains in regions 'A' and 'B' of 19\% alloying elements was significantly finer than the grain size of $9 \%$ alloying elements. This was due to the $9 \%$ alloying element of flux bands into the molten pool was theoretically calculated to be $0.7 \%$ and the $19 \%$ was $1.48 \%$. According to the influence of alloy amount on the continuous cooling transition curve of weld 

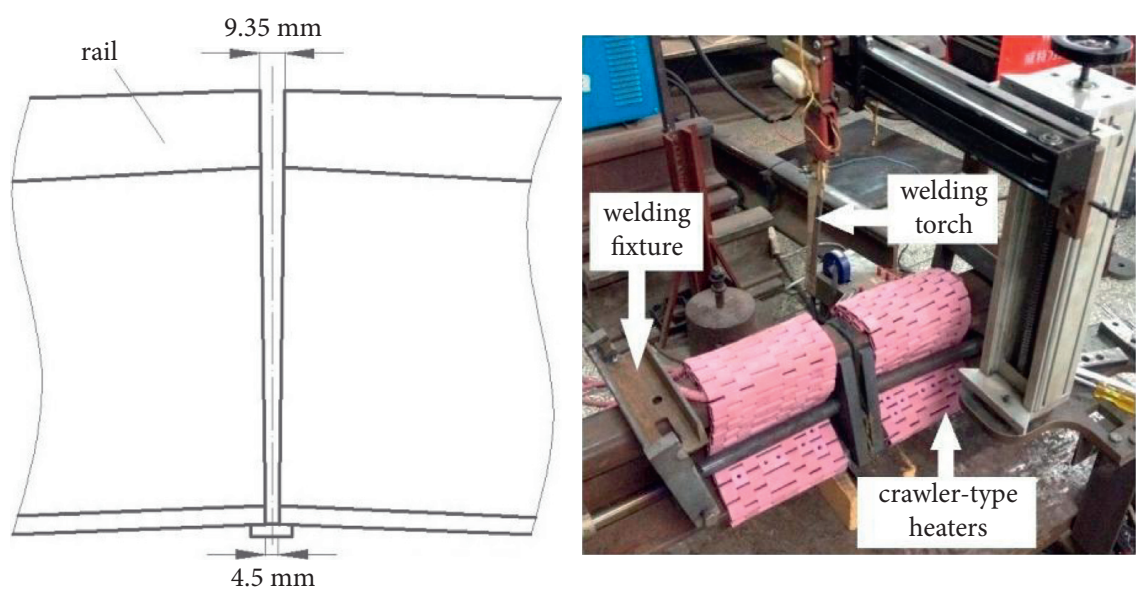

(a)
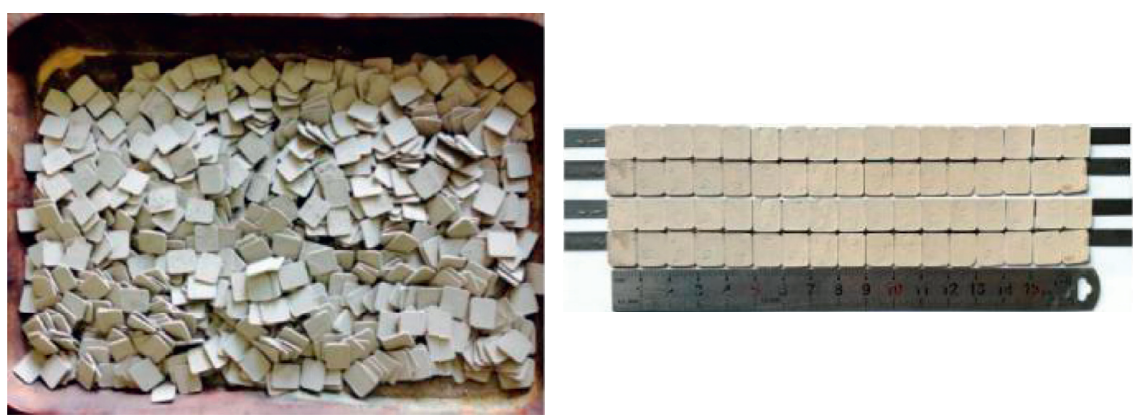

(b)

FIgURe 2: Real picture of rail ultranarrow gap welding device. The picture of (a) groove and (b) flux band.

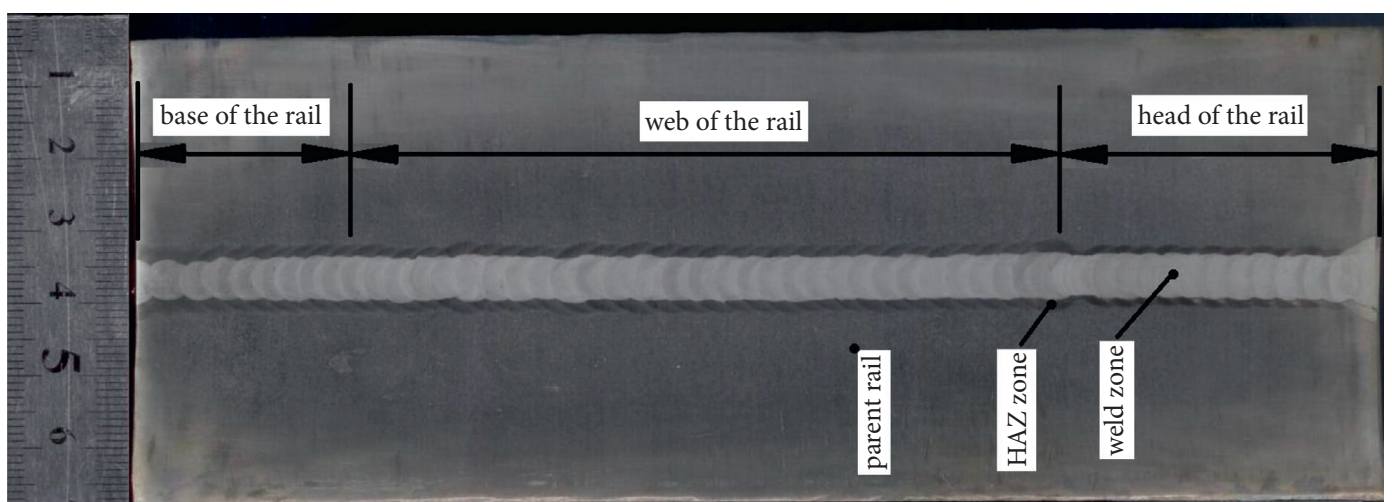

FIgURE 3: Macroscopic picture of the rail weld joint cross section.

metal, it could be known that increasing the quality of alloying elements would cause the transition curve to move to the right, and the high-temperature phase transition microstructure of weld metal would decrease, while the medium-temperature phase transition microstructure would increase and the grain would be refined [24].

\subsection{Mechanical Properties}

3.2.1. Weld Metal Hardness. Figure 6 presents the hardness distribution curve of the welded joint at the head of the rail of three flux formulations. As shown, the average hardness of the parent pearlitic rail steel was $24.8 \mathrm{HRC}$, while that of the pearlitic HAZ was $35.8 \mathrm{HRC}$. The hardness of the weld was found increase with the increasing amount of the alloying element of the flux bands. When no alloying composition was added in the flux bands, the average hardness of the weld zone was 17.9 HRC, which was only $69.4 \%$ of the base metal. When $9 \%$ alloying element was added to the flux bands, the average hardness of the weld zone was $22.5 \mathrm{HRC}$, which was just $93.1 \%$ of the base metal. And when the alloying composition content reached $19 \%$, the average hardness of the weld zone was $25.0 \mathrm{HRC}$, which has reached $101.2 \%$ of the rail base material, and the 


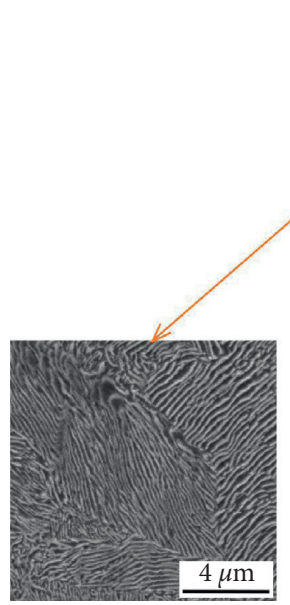

(a)

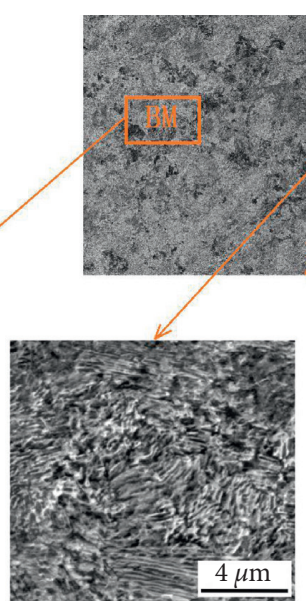

(b)

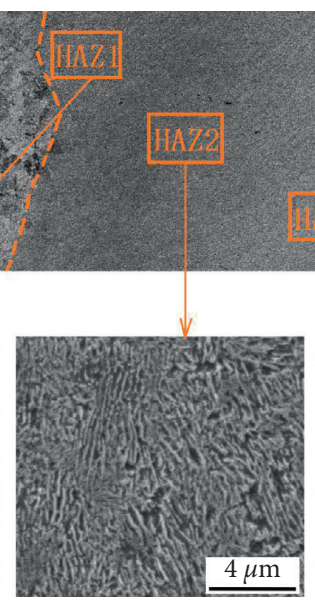

(c)

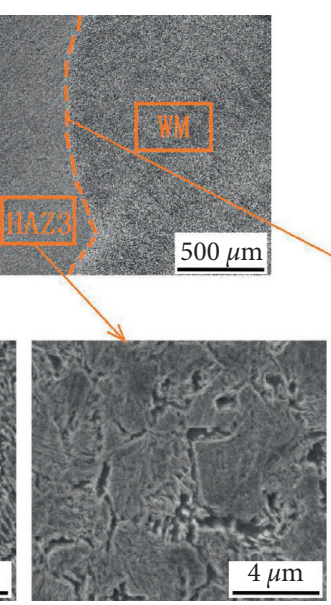

(d)

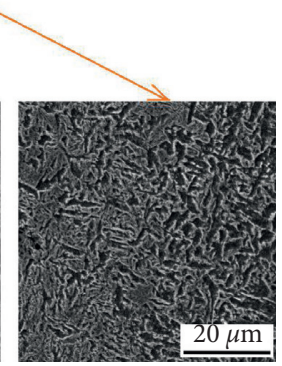

(e)

Figure 4: Microstructure of ultranarrow gap weld metals jointed: (a) base metal, (b) incomplete recrystallized zone, (c) recrystallized zone, (d) overheated zone, and (e) fusion zone.

corresponding welded joints could meet the requirement of high-speed railway (China's hardness inspection standards for high-speed railway welding joint hardness should be equivalent to $95 \% \sim 105 \%$ of the rail base material hardness) [25].

According to the above results, it could be seen that the HAZ has the highest hardness, which was attributed to the lower heat input used in ultranarrow gap welding. The temperature field distribution in the welding process was low, and the temperature of conduction to the heataffected zone was lower. After the metal in the heat-affected zone was austenitized, due to the rapid cooling of the weld metal, the austenite formed in the heat-affected zone had no time to grow, so the grain structure formed in the area was refined, and the sorbite or troostite formed after cooling was smaller than the pearlite of the parent material. The hardness of the weld zone increased with the increase of alloying element content, which could be analyzed as follows: the microstructure of the ultranarrow gap weld zone all belonged to different morphologies of ferrite, while ferrite belonged to the soft phase [26], so the hardness of the ultranarrow gap weld zone was generally low. However, with the increase of alloying element content, the weld microstructure was obviously refined. Under the same soft phase microstructure, the hardness increased with the decrease of grain size. And the addition of molybdenum in the flux would make the weld metal solid solution hardening, so the hardness of the weld zone increased significantly with the increase of alloy element content [27].

3.2.2. Tensile Properties. The effects of the flux formulations 2 and 3 on the UTS of the welded specimens were evaluated, and the results are given in Table 3 . The average ultimate tensile strength of the ultranarrow welded specimen was observed as $810 \mathrm{MPa}$ (the flux formulation (2). According to $\mathrm{TB} / 1632.2-2014$, the tensile strength of the U71Mn rail welded joint for flash welding was $\mathrm{Rm} \geq 800 \mathrm{MPa}$ and
$A \geq 6 \%$. The fracture location of the formulation 2 and 3 specimens is shown in Figure 7. An elongation of 9.6\% was observed in the flux formulation 2 welded specimen. The tensile strength and percentage elongation of the flux formulation 3 welded sample were observed as $876 \mathrm{MPa}$ and $6.5 \%$, respectively. It could be known that the tensile properties of welded joints obtained by ultranarrow gap welding meet the quality requirements of rail flash welded joints.

3.2.3. Charpy Impact Toughness of Welds. The average value of Charpy impact energy for two tested specimens is listed in Table 4. Clearly, the toughness values appeared to be a function of the $\mathrm{Ni}, \mathrm{Mo}, \mathrm{Cr}$, and $\mathrm{Mn}$ content of the metals. As a result, the Charpy impact energy of specimen formulation 2 and formulation 3 decreased drastically with the decrease in temperature, and it did not change until the temperature decreased to lower than $-60^{\circ} \mathrm{C}$. The macroscopic morphology of an impact fracture is shown in Figure 8. At $20^{\circ} \mathrm{C}, 0^{\circ} \mathrm{C}$, and $-20^{\circ} \mathrm{C}$, there were only shear lip zone and fiber zone in macroscopic impact fracture, and the morphology of the microscopic fracture was dimpled with different sizes, as shown in Figures 9(a) and 9(b), which was a typical ductile fracture. With the decrease of temperature, the dimple size decreased obviously. When the fracture condition was consistent, the larger and more uniform dimple size, the better the ductility of the material, so the impact energy at $20^{\circ} \mathrm{C}$ was higher than that at $-20^{\circ} \mathrm{C}$. When the temperature dropped to $-40^{\circ} \mathrm{C}$, the macroscopic fracture consisted of the fiber zone, shear lips, and radiation zone, and the radiation zone increased with the decrease of temperature. The shear lip area near the root of the sample notch, bottom, and edge were all dimples, and the dimples were uniformly small in size, as shown in Figure 9(c). However, away from the root notch, at $-40^{\circ} \mathrm{C}$, the fracture showed the coexistence of a quasicleavage fracture surface and a dimple, so the impact toughness decreased a little at $-40^{\circ} \mathrm{C}$. At $-60^{\circ} \mathrm{C}$, the number of dimples on the fracture surface decreased significantly, and the whole fracture appeared to be a quasicleavage fracture. With the 

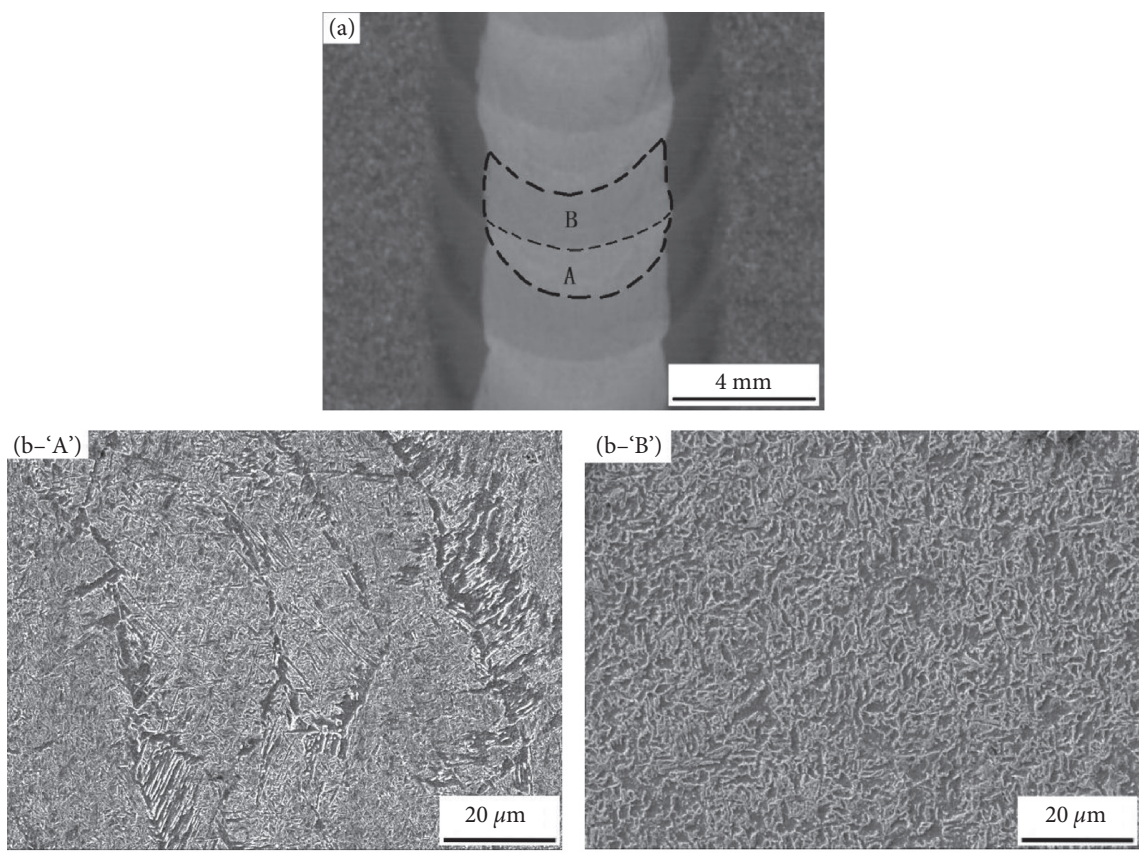

(b)
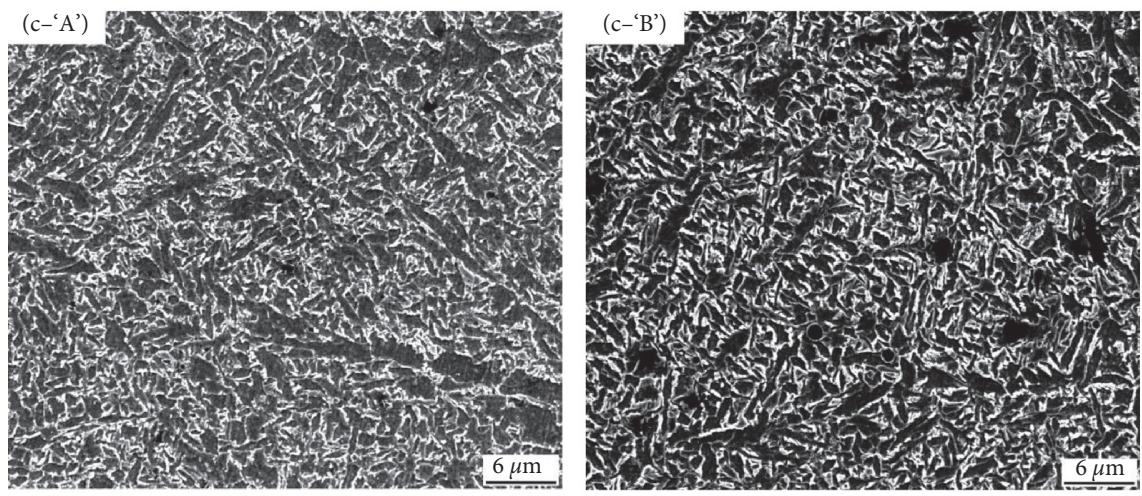

(c)
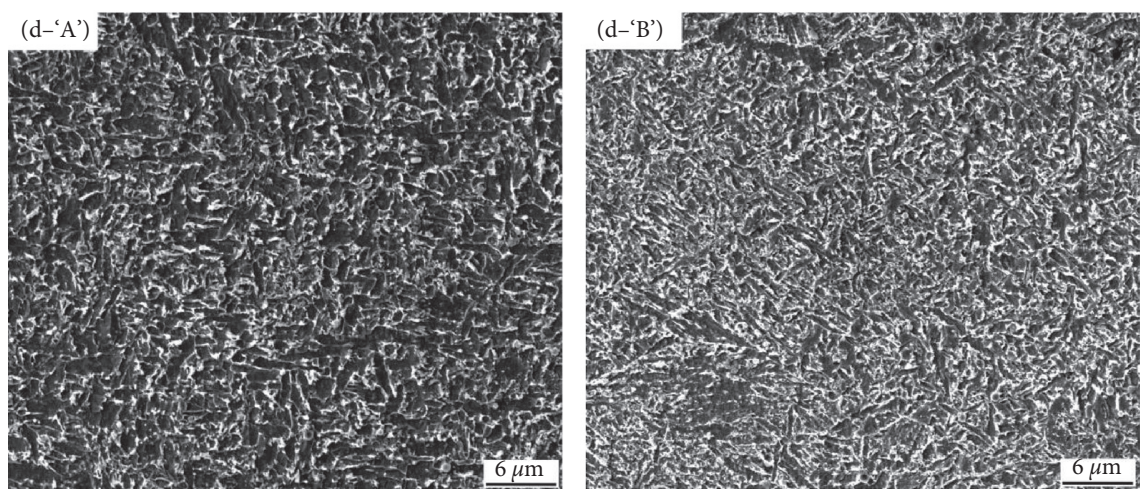

(d)

Figure 5: The microstructure of weld metal: (a) macroscopic picture of weld metal, (b) $0 \%$ alloying element, (c) $9 \%$ alloying element, and (d) $19 \%$ alloying element.

decrease of temperature, the fracture toughness deteriorated, and the impact energy decreased obviously at $-60^{\circ} \mathrm{C}$ and $-80^{\circ} \mathrm{C}$.

The curve of Charpy impact energy versus temperature can be divided into three regions, as shown in Figure 10, the lower shelf, the transition region, and the upper shelf. The lower shelf corresponded to the "brittle" mechanism of fracture, such as intergranular cleavage. As the temperature increased, a combination fracture mechanism of brittle and ductile was achieved corresponding to the transition region. If the temperature increased even further, the fracture 


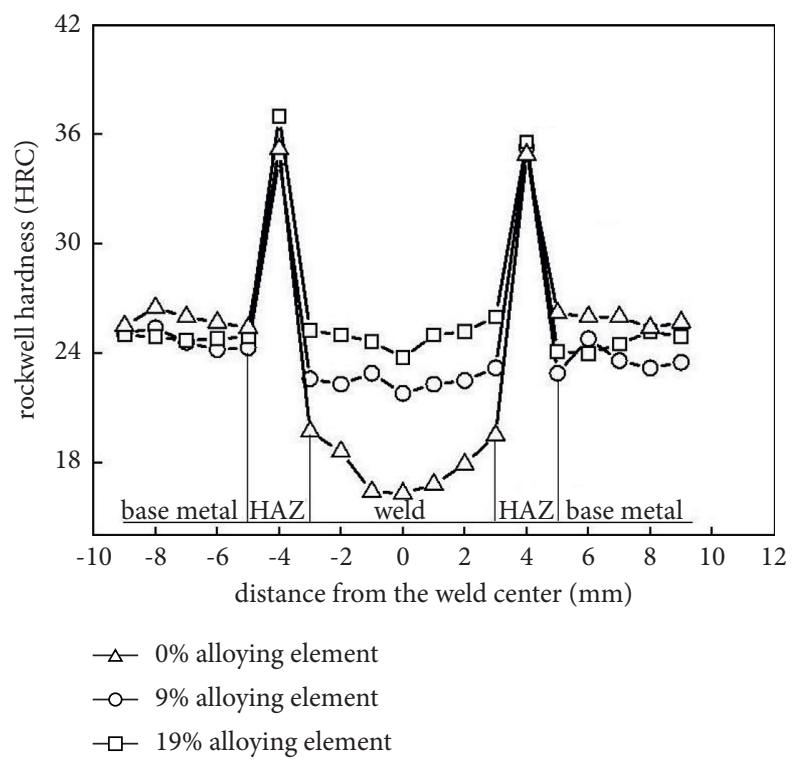

Figure 6: Hardness of rail steel versus distance to the center of the weld.

TABLE 3: Effect of flux formulation on the ultimate tensile strength of the weld joints.

\begin{tabular}{lcccccc}
\hline Flux formulation & & Specimen 1 & Specimen 2 & Specimen 3 & Specimen 4 & Average \\
\hline \multirow{2}{*}{ Formulation 2 } & Ultimate tensile strength (MPa) & 826 & 797 & 831 & 787 & 810 \\
& Percentage elongation after fracture & 7.9 & 10.1 & 13.9 & 6.6 & 9.6 \\
\hline \multirow{2}{*}{ Formulation 3 } & Ultimate tensile strength (MPa) & 889 & 930 & 853 & 833 & 876 \\
& Percentage elongation after fracture & 6.9 & 6.1 & 6.6 & 6.3 \\
\hline
\end{tabular}

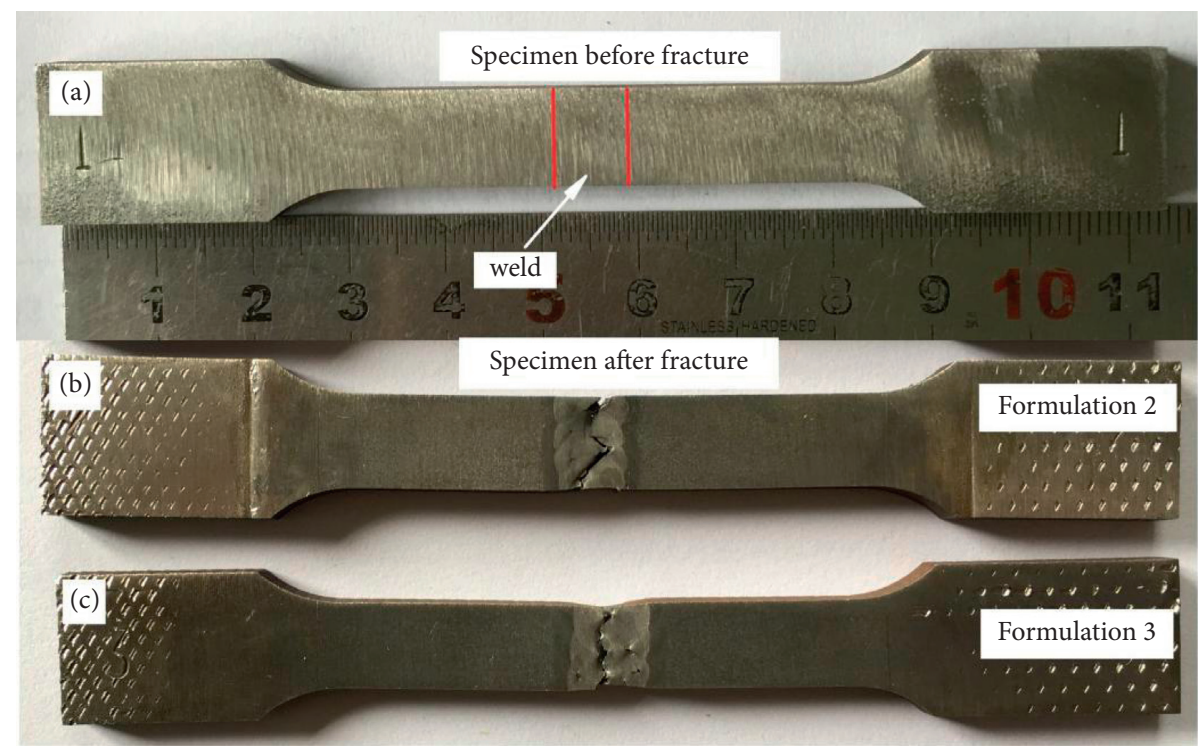

Figure 7: (a) Tensile test specimens before fracture, (b) the flux formulation 2 tensile test specimens after fractures, and (c) the flux formulation 3 tensile test specimens after fractures.

mechanism would transition to completely void ductile growth and coalescence type fibrous fracture corresponding to the upper shelf.

It was revealed that the Charpy impact energy of specimen formulation 2 was higher than that of formulation 3 at six temperature points, and the ductileto-brittle transition temperature of specimen formulation 2 was a little lower than that of formulation 3. It was clearly attributed to the presence of a higher amount of $\mathrm{Ni}, \mathrm{Mo}, \mathrm{Cr}$, and Mn in the weld metal. Normally, higher 
TABLE 4: Charpy impact energy (Ak) of U71Mn ultranarrow rail welds.

\begin{tabular}{|c|c|c|c|c|c|c|}
\hline \multirow{2}{*}{$\mathrm{T}\left({ }^{\circ} \mathrm{C}\right)$} & \multicolumn{3}{|c|}{ Formulation 2 weld $(\mathrm{AKU} / \mathrm{J})$} & \multicolumn{3}{|c|}{ Formulation 3 weld (AKU/J) } \\
\hline & 1 & 2 & Average & 1 & 2 & Average \\
\hline 20 & 95.5 & 86.5 & 91 & 67.9 & 57.5 & 62.7 \\
\hline 0 & 88.6 & 80.4 & 84.5 & 52.4 & 66.3 & 59.35 \\
\hline-20 & 84 & 70.6 & 77.3 & 55.8 & 48.8 & 52.3 \\
\hline-40 & 73.4 & 69.3 & 71.35 & 36.1 & 38.5 & 37.3 \\
\hline-60 & 52 & 38.5 & 45.25 & 14.5 & 14.1 & 14.3 \\
\hline-80 & 37.5 & 55 & 46.25 & 14.1 & 14.9 & 14.5 \\
\hline
\end{tabular}

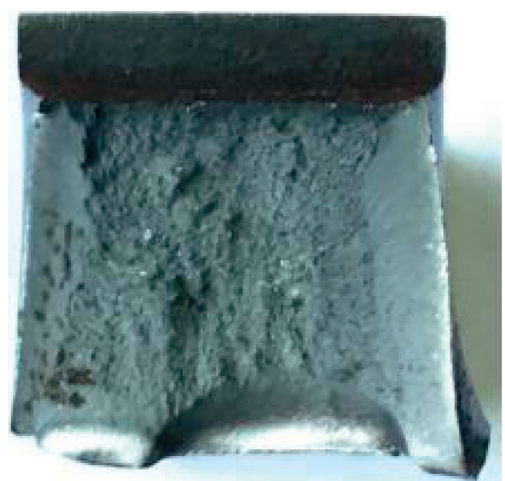

(a)

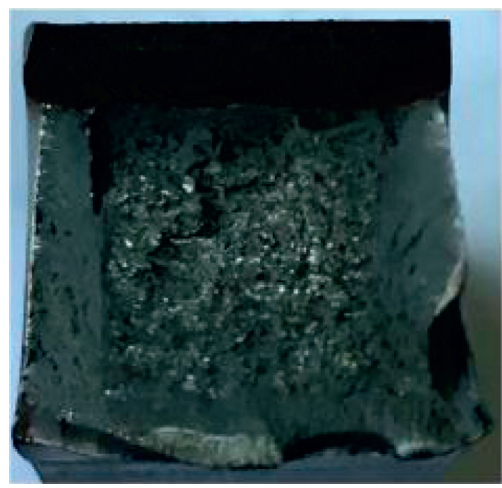

(d)

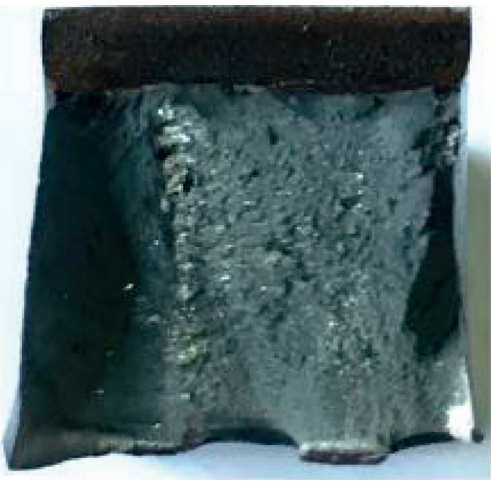

(b)

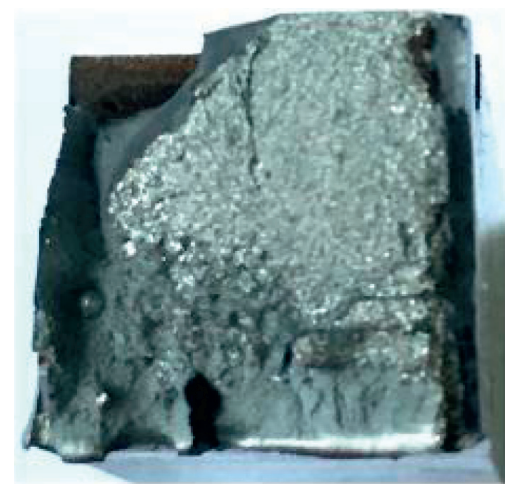

(e)

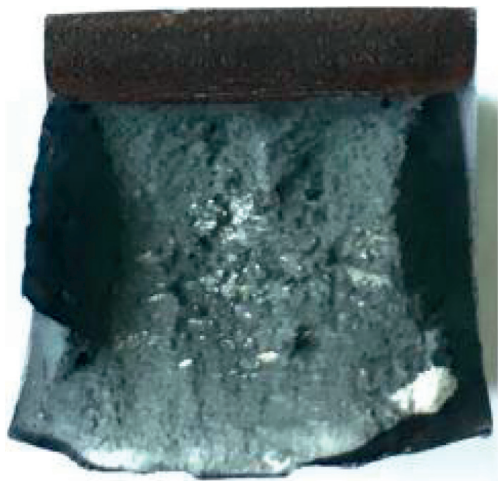

(c)

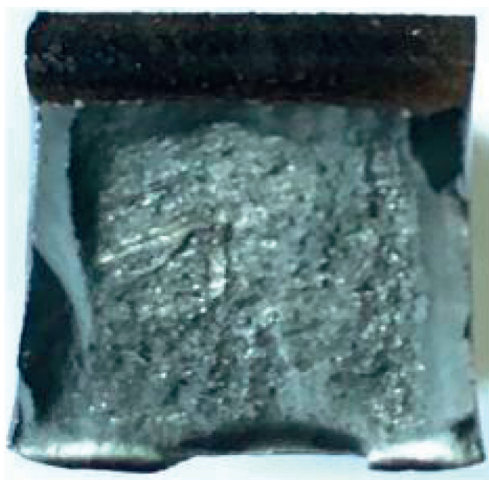

(f)

Figure 8: The macromorphology of impact fracture of the notch at different temperatures in the center of the weld. (a) $20^{\circ} \mathrm{C}$, (b) $0^{\circ} \mathrm{C}$, (c) $-20^{\circ} \mathrm{C},(\mathrm{d})-40^{\circ} \mathrm{C},(\mathrm{e})-60^{\circ} \mathrm{C}$, and (f) $-80^{\circ} \mathrm{C}$.

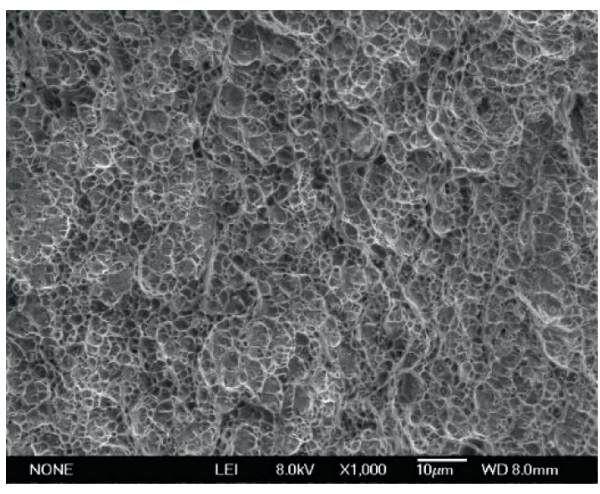

(a)

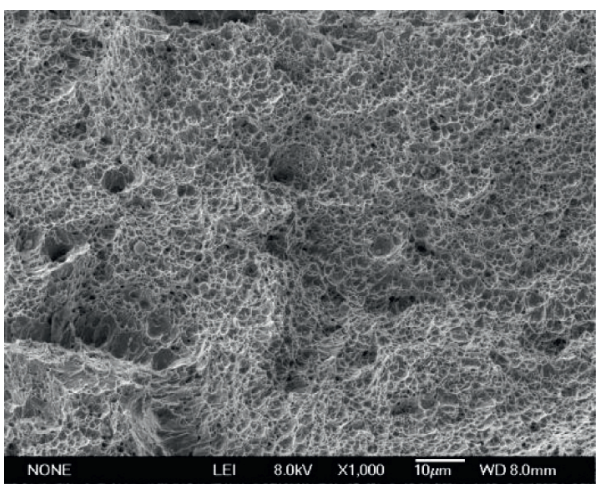

(b)

Figure 9: Continued. 


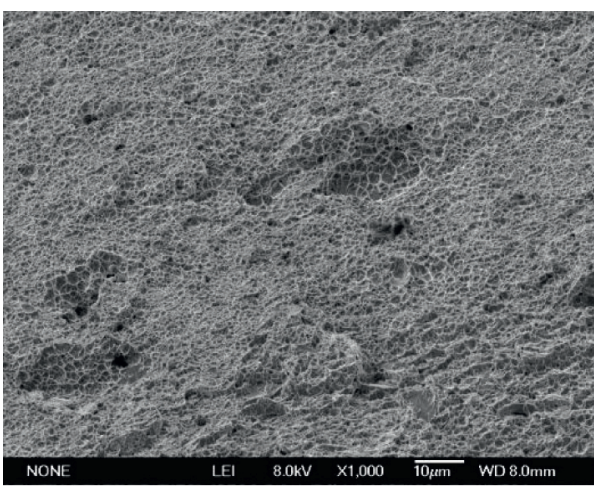

(c)

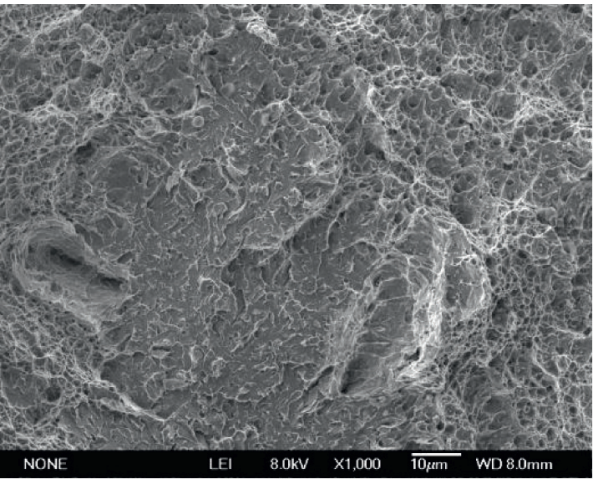

(d)

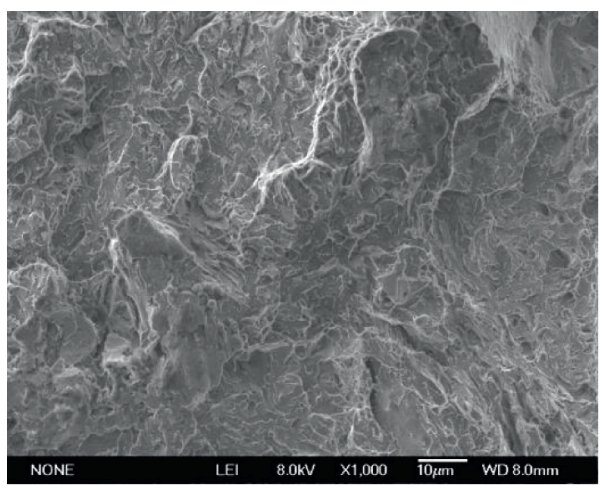

(e)

Figure 9: The micromorphology of the impact fracture at different temperatures in the center of the weld. (a-c) Ductile fracture morphology and (d, e) brittle fracture morphology. (a) $20^{\circ} \mathrm{C}$, (b) $-20^{\circ} \mathrm{C},(\mathrm{c})-40^{\circ} \mathrm{C}, 60^{\circ} \mathrm{C},(\mathrm{d})-40^{\circ} \mathrm{C}$, and (e) $-60^{\circ} \mathrm{C}$.

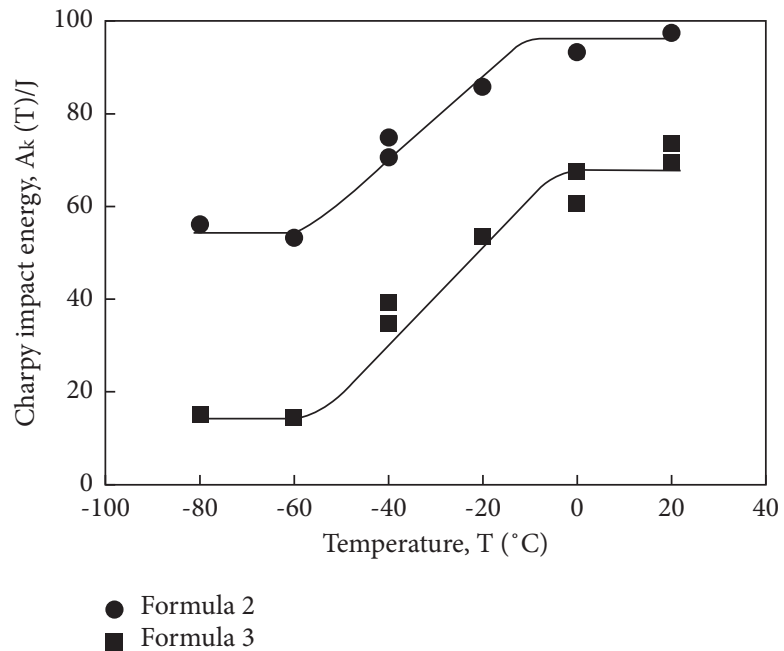

FiguRE 10: Charpy temperature transition curves of ultrnarrow rail welds.

alloying element content indicates higher tensile strength and lower toughness.

\section{Conclusions}

(1) The microstructure of the HAZ zone in ultranarrow gap welded rails consists of fine pearlite. The microstructure of the weld bead consists of acicular ferrite. The alloying composition of the flux band significantly influences the final microstructure of the dissimilar weld zone.

(2) The hardness of the weld is found to be increased with the increase of the amount of the alloying element of the flux bands, and when the alloying element reached $19 \%$, the hardness of the weld zone 
reached $101.2 \%$ of that of the rail base material. The ultimate tensile strength of formulation 2 is lower than that of formulation 3, while the percentage elongation after fracture of formulation 2 is higher than that of formulation 3. The Charpy impact energy of specimen formulation 2 is higher than that of formulation 3 from -80 to $+20^{\circ} \mathrm{C}$, and the ductile-tobrittle transition temperature of specimen formulation 2 is lower than formulation 3.

(3) By comprehensive comparison of mechanical properties (hardness, ultimate tensile strength, and Charpy impact energy) between flux formulation 2 and flux formulation 3, the joint properties obtained from flux formulation 3 are better. This investigation has demonstrated the feasibility of producing an ultranarrow gap welded joint of pearlitic rail steel that is predominantly homogeneous and of ferrite microstructure.

\section{Data Availability}

The data used to support the findings of this study are available from the corresponding author upon request.

\section{Conflicts of Interest}

The authors declare that there are no conflicts of interest.

\section{Acknowledgments}

The authors gratefully acknowledge the financial support of the Natural Science Foundation of Chongqing (grant number: cstc2020jcyj-msxmX0102) and the Scientific and Technological Research Program of Chongqing Municipal Education Commission (grant numbers: KJQN201801333, KJQN201801334, and KJQN201901309).

\section{References}

[1] H. Su, C. L. Pun, P. Mutton, Q. Kan, G. Kang, and W. Yan, "Numerical study on the ratcheting performance of rail flash butt welds in heavy haul operations," International Journal of Mechanical Sciences, vol. 199, no. 7, Article ID 106434, 2021.

[2] M. Messaadi, I. Grossoni, P. Shackleton, I. Shevtsov, Y. Bezin, and R. Dollevoet, "Rail degradation due to thermite weld discontinuities: field experience," Engineering Failure Analysis, vol. 128, no. 8, Article ID 105585, 2021.

[3] N. N. Voronin, N. B. Seydakhmetov, and V. A. Rezanov, "The influence of technological parameters on the thermal cycle at butt flash welding of rails," Welding International, vol. 33, pp. 1-7, 2021.

[4] X. Yu, L. Feng, S. Qin, Y. Zhang, and Y. He, "Fracture analysis of U71Mn rail flash-butt welding joint," Case Studies in Engineering Failure Analysis, vol. 4, no. C, pp. 20-25, 2015.

[5] N. Ma, Z. Cai, H. Huang, D. Deng, H. Murakawa, and J. Pan, "Investigation of welding residual stress in flash-butt joint of U71Mn rail steel by numerical simulation and experiment," Materials \& Design, vol. 88, no. 25, pp. 1296-1309, 2015.

[6] R. Ma, D. Huang, J. Zhang, Y. Zhang, and Q. Lv, "Effects of rail flash-butt welding and post-weld heat treatment processes meeting different national standards on residual stresses of welded joints," International Journal of Materials Research, vol. 111, 2020.

[7] Y. Liu, "Investigation on material characteristics and fatigue crack behavior of thermite welded rail joint," Construction and Building Materials, vol. 276, no. 4, 2021.

[8] R. Wang, L. I. Dadong, and L. U. Xin, "Cause analysis of unacceptable hardness and microstructure for postweld heat treatment of U71MnH rail joints," Railway Quality Control, vol. 47, no. 6, pp. 29-35, 2019.

[9] Y. Q. Wang, Z. Hui, Y. J. Shi, and B.-R. Feng, "Mechanical properties and fracture toughness of rail steels and ite welds at low temperature," International Journal of Minerals Metallurgy and Materials, vol. 19, no. 5, pp. 409-420, 2012.

[10] B. L. Josefson, R. Bisschop, M. Messaadi, and J. Hantusch, "Residual stresses in thermite welded rails: significance of additional forging," Welding in the World, Le Soudage Dans Le Monde, vol. 64, no. 7, pp. 1-18, 2020.

[11] L. Yang, K. S. Tsang, H. J. Hoh, X. Shi, and J. Hock LyePang, "Structural fatigue investigation of transverse surface crack growth in rail steels and thermite welds subjected to in plane and out of plane loading," Engineering Structures, vol. 204, Article ID 110076, 2019.

[12] T. Shi, Z. Zhao, D. Zou, Q. Yang, X. Sun, and Y. Wang, Fracture Failure Analysis of Thermite Welded Joint of Rail, China Railway, Beijing, China, 2019.

[13] L. Gong and Z. Liang, "Ultra-narrow gap welding with constrained arc by flux band applied to rail welding," Electric Welding Machine, vol. 46, no. 8, pp. 43-47, 2016.

[14] L. Zhu, S. Zheng, and J. Chen, "Development of ultra-narrow gap welding with constrained arc by flux band," China Welding, vol. 15, no. 2, pp. 44-49, 2006.

[15] S. Zheng, Y. Li, W. Shi, and X. Zhao, "Microstructure and mechanical properties of q235/1Cr18Ni9Ti dissimilar steel joints welded with ultra-narrow gap," Transactions of the China Welding Institute, vol. 40, no. 8, pp. 38-43, 2019.

[16] L. Zhu, L. Xiao, A. Zhang, Q. Liu, and X. Wang, "Research on ultra narrow gap welding of groove rail and frog," Welding, vol. 2, pp. 1-4, 2020.

[17] N. Mukai, Y. Inoue, S. Sasakura, and Y. Kinoshita, "Prevention of cold cracking by the welding process for reducing diffusible hydrogen in high-tensile thick plate welding," Welding International, vol. 33, no. 6, pp. 1-13, 2021.

[18] L. Gong, L. Zhu, and H. X. Zhou, "Effect on hardness and microstructures of rail joint with ultra-narrow gap arc welding by post weld heat treatment," Key Engineering $M a$ terials, vol. 737, pp. 90-94, 2017.

[19] J. Lin, X. Wang, Y. Lei, R. Wei, and F. Guo, "Study on hot cracking in laser welded joints of inconel 718 alloy foils," Journal of Manufacturing Processes, vol. 64, pp. 1024-1035, 2021.

[20] L. Gong, L. Zhu, and C. Zhou, "Influence of welding process parameters on hot crack in ultra-narrow gap welding," Transactions of the China Welding Institute, vol. 37, no. 10, pp. 93-96, 2016.

[21] L. Wang, J. Qiao, and J. Chen, "The mechanism of effect of flux bands on the arc behavior in flux bands constricting arc welding process," Materials, vol. 13, no. 7, 2020.

[22] P. Fu, L. Zhu, C. Zhou, and W. Shang, "Angular distortion of the rail butt joint welded with the method of ultra-narrow gap welding," Electric Welding Machine, vol. 9, pp. 46-48, 2013.

[23] L. Zhu, H. Wang, and P. Fu, "Welding test of ultr-narrow gap of rail butt," Welding Research, vol. 3, p. 4, 2012.

[24] A. Ba and B. Cp, "Study on effect of grain refinement of P92 steel base plate on mechanical and microstructural features of 
the welded joint," International Journal of Pressure Vessels and Piping, vol. 192, Article ID 104426, 2021.

[25] H. Y. Che, Z. P. Cai, and Q. U. Yue-Bo, "Effect of normalizing temperature on hardness and microstructure of rail joints with narrow-gap automatic arc welding," Materials for $\mathrm{Me}$ chanical Engineering, vol. 35, 2011.

[26] H. Mansouri and A. Monshi, "Microstructure and residual stress variations in weld zone of flash-butt welded railroads," Science and Technology of Welding \& Joining, vol. 9, no. 3, pp. 237-245, 2004.

[27] A. Allie, H. Aglan, and M. Fateh, "Microstructure-fracture behavior relationships of slot-welded rail steels," Metallurgical and Materials Transactions A, vol. 42, 2011. 